\title{
Carer's perception of and reaction to reassurance seeking in obsessive compulsive disorder
}

Article

Published Version

Kobori, O., Salkovskis, P. M., Pagdin, R., Read, J. and Halldorsson, B. (2017) Carer's perception of and reaction to reassurance seeking in obsessive compulsive disorder. The Cognitive Behaviour Therapist, 10. e7. ISSN 1754-470X doi: https://doi.org/10.1017/S1754470X17000095 Available at https://centaur.reading.ac.uk/72164/

It is advisable to refer to the publisher's version if you intend to cite from the work. See Guidance on citing.

To link to this article DOI: http://dx.doi.org/10.1017/S1754470X17000095

Publisher: Cambridge University Press

All outputs in CentAUR are protected by Intellectual Property Rights law, including copyright law. Copyright and IPR is retained by the creators or other copyright holders. Terms and conditions for use of this material are defined in the End User Agreement.

www.reading.ac.uk/centaur 
Central Archive at the University of Reading

Reading's research outputs online 


\title{
Carer's perception of and reaction to reassurance seeking in obsessive compulsive disorder
}

\author{
Osamu Kobori' ${ }^{1 *}$, Paul M. Salkovskis ${ }^{2}$, Rowena Pagdin ${ }^{3}$, Julie $\operatorname{Read}^{4}$ and \\ Brynjar Halldorsson ${ }^{5}$
}

${ }^{1}$ Department of Psychology, Swansea University, UK

${ }^{2}$ Department of Psychology, University of Bath, $U K$

${ }^{3}$ Avon and Wiltshire Mental Health Partnership NHS Trust

${ }^{4}$ Institute of Psychiatry, King's College London, UK

${ }^{5}$ School of Psychology and Clinical Language Science, University of Reading, UK

Received 10 February 2017; Accepted 30 June 2017

\begin{abstract}
The purpose of the present study was to explore the experience of being asked for reassurance from the perspective of carers of obsessive compulsive disorder (OCD) sufferers, and to examine its relationship to sufferers' reassurance seeking by a direct comparison with data obtained from the person they normally offer reassurance to. Forty-two individuals with OCD and their carers completed alternate versions of the Reassurance Seeking Questionnaire. Result suggest that carers report most commonly providing reassurance when asked to do so, and the frequency of their reassurance provision is associated with how carefully sufferers seek reassurance, rather than their OCD symptom severity. The carer's perspectives on the impact of reassurance provision was accurate; both sufferers and carers perceive that reassurance works only temporarily, but even if the anxiety-relieving effect of reassurance decreases in the medium term, it is likely to be perceived as beneficial because carers accurately perceived that sufferers would feel much worse if they refused to provide reassurance. The present study is the first to quantitatively investigate carer's experiences of reassurance provision, and elucidate why carers feel the need to provide it.
\end{abstract}

Key words: reassurance seeking, carers, obsessive compulsive disorder, family accommodation

\section{Introduction}

\section{Family in mental health problems}

Families play a vital role in supporting those with mental health problems. Investigation of the impact of anxiety disorders in families forms a small yet expanding area of work (Lochner et al., 2003), with only modest quantitative and qualitative differences in 'burden of care' when compared with severe mental illness such as psychosis (e.g. Veltro et al., 1994).

\footnotetext{
${ }^{*}$ Correspondence to Osamu Kobori, Department of Psychology, Swansea University, Singleton Park, Swansea SA2 8PP, UK. E-mail: O.Kobori@swansea.ac.uk
} 
The impact of obsessive compulsive disorder (OCD) on family functioning has received the greatest research attention compared with other anxiety problems. A review of family burden in OCD found evidence of a high degree of family dysfunction, particularly relating to conflict, distress and marital discord (Steketee, 1997). Black et al. (1998) reported increased disruption to family, social and personal life, due to anger, conflict, fatigue and marital discord in the OCD group, whilst Derisley et al. (2005) found parents with an OCD child had poorer mental health and used more avoidant coping strategies. Surveys report a common perception of negative impact on family life, where OCD is a feature, both by the individual with OCD (Stein et al., 1996) and the wider family, including parents, partners, children and siblings (Cooper, 1996).

\section{Family accommodation in $\mathrm{OCD}$}

Family members of OCD sufferers often feel obliged to collude with compulsive rituals typically referred to as family accommodation. Calvocoressi et al. (1995) reported some degree of family accommodation in 30 of 34 caregiving relatives, noting that threats of violence ensured 'accommodation' in some more extreme cases. The interpersonal impact has been demonstrated by a wealth of research showing that caring for someone with OCD is associated with significant caregiver burden, psychological distress and reduced quality of life (Abreu Ramos-Cerqueira et al., 2008; Cicek et al., 2013; Grover and Dutt, 2011; Kalra et al., 2009; Torres et al., 2012; Vikas et al., 2011).

Family accommodation involves participation in rituals, modification of personal and family routines, facilitating avoidance, and taking on the sufferer's responsibilities. Examples include engaging in excessive hand washing to help reduce contamination fears experienced by a loved one, listening to repeated confessions of a relative who feels the need to constantly confess, providing excessive reassurance and/or removing knives to reduce or alleviate the distress of a relative with aggressive or suicidal obsessions (Lebowitz et al., 2016). In order to reduce anxiety (Halldorsson et al., 2016), these behaviours may also help the family or couple to get through daily routines more efficiently. However, accommodation is associated with parental distress in paediatric OCD (Storch et al., 2009) and with anxiety and depression in relatives of adults with OCD (Amir et al., 2000). Different methods have been employed to assess accommodating behaviours in relatives of OCD sufferers. For example, Shafran et al. (1995) administered a self-administered questionnaire to 88 family members of individuals with obsessive-compulsive symptoms and revealed that $60 \%$ of the family members were involved to some extent in rituals with the affected family member (Shafran et al., 1995). Nearly all the family members reported at least some degree of interference in their lives. Information was also gathered about the type of rituals in which members were involved, how they responded to the demands of the affected relative to engage in the rituals, their beliefs and knowledge about compliance, and the degree to which the rituals interfered in their lives (Shafran et al., 1995).

Excessive accommodation of compulsions runs counter to exposure-based therapy instructions and may instead reinforce symptoms and also increase relatives' distress (Steketee and Pruyn, 1998). Amir et al. (2000) reported that OCD sufferers whose relatives modified their schedules or otherwise accommodated their symptoms had a worse response to behavioural therapy. Correspondingly, helping family members disengage from compulsions 
and resist accommodation during behavioural therapy appeared to improve OCD sufferers' outcomes (Grunes et al., 2001; Van Noppen and Steketee, 2009).

Another group developed a clinician-administered instrument, the Family Accommodation Scale (FAS), which assesses the nature and frequency of accommodating behaviours of family members of people with OCD (Calvocoressi et al., 1995, 1999). Calvocoressi et al. (1999) reported that family accommodation was present for $88 \%$ of spouses and parents and correlated significantly with sufferer symptom severity, family dysfunction, and relatives' stress. Most relatives reported that they were actually trying to attenuate sufferer distress or anger and decrease compulsions/rituals (Calvocoressi et al., 1995). More recently, Boeding et al. (2013) examined accommodating behaviours in partners of adults with OCD. As part of a treatment study, 20 couples were assessed for accommodating behaviours, OCD symptoms, and relationship functioning before and after 16 sessions of cognitive behavioural treatment. Partner-reported accommodation was associated with the sufferer's OCD symptoms at pretreatment, and negatively associated with the partners', but not the sufferers', self-reported relationship satisfaction. Post-treatment partner accommodation was also associated with poorer response to treatment (Boeding et al., 2013).

\section{Reassurance seeking and provision within the context of $O C D$}

Reassurance seeking occurs across the full range of OCD presentations. For example, individuals with OCD may ask others whether something is clean, whether they have done something properly, whether they are truly religious/heterosexual and so on. Clinical descriptions of reassurance seeking in the OCD literature have generally equated this behaviour to other compulsive or 'neutralizing' acts. Rachman (2002) proposes that excessive reassurance seeking, compulsive checking, and other forms of OCD-related neutralizing behaviour can all be construed as strategies intended both to reduce the likelihood of negative outcomes (i.e. reducing 'threat'), and to reduce one's perceived responsibility for such outcomes.

Studies of family accommodation revealed that family members provide reassurance to sufferers. For example, Calvocoressi et al. (1995) interviewed sufferers and their family members and found that one-third of the relatives often reassured the sufferers, participated in the compulsions and assumed responsibility for activities usually carried out by the sufferers. Few empirical studies have investigated the way sufferers seek reassurance and the way reassurance seeking and its provision cause interpersonal difficulties in particular. Recently, Kobori and Salkovskis (2013) developed the Reassurance Seeking Questionnaire (ReSQ) and conducted it with 153 individuals with OCD. They found that the more individuals with OCD trust the resource, the more repeatedly they seek reassurance from it. From the carer's point of view, this result suggests that they would feel not trusted, because no matter how many times they answer, they are repeatedly asked the same question. The specific ways of seeking reassurance could also cause interpersonal problems. Both quantitative (Kobori and Salkovskis, 2013) and qualitative (Kobori et al., 2012) studies suggest that individuals with OCD seek reassurance very carefully. They become very careful about composing the right question (sometimes tricking to obtain a convincing answer) and may also use discrete ways of seeking reassurance to mask their reassurance seeking. They also become very careful about receiving reassurance. For example, they listen very carefully to the answer, they scrutinize the other person's facial expression to gauge how confident they are with the answer, and 
they show frustration when the person offering reassurance gives an ambiguous response or does not seem to think seriously. However, little is known about how carers experience and perceive reassurance seeking and providing. One qualitative study (Halldorsson et al., 2016) interviewed carers of OCD patients, and findings revealed that excessive reassurance seeking commonly leads to relationship problems and feelings of frustration. However, whilst carers are fully aware of the counter-productive nature of giving reassurance for the maintenance of OCD, they feel unable to cope day-to-day without giving reassurance.

\section{The purpose of the present study}

The purpose of the present study was to examine carers' experience of reassurance providing and its relationship to the psychopathology of the sufferers. We focused on the specific area of reassurance seeking rather than the more general area of family accommodation in order to examine in detail the relationship between reassurance seeking and provision. Specifically, we first examined the carer's general account of reassurance provision and its relationship to psychopathology of the sufferers. Secondly, we evaluated carers' emotional reactions when they provide and do not provide reassurance. Finally, we examined the correspondence between the experience of OCD sufferers and their carers in terms of their response to providing reassurance (or not).

\section{Method}

\section{Overview}

This study is part of a larger project which aims to investigate the phenomenology, functions, and people's perceptions of reassurance seeking in anxiety disorders. This project has been reviewed by the Joint South London and Maudsley and the Institute of Psychiatry NHS Research Ethics Committee (REC reference: 07/Q0706/39). The questionnaires were either posted to the participants or taken away by the OCD suffers who took part in the experiment about reassurance seeking. Participants were recruited from an out-patient service at the Institute of Psychiatry, King's College London or the charity organizations for OCD (OCDUK, OCD Action) and anxiety (Anxiety UK). They received two questionnaires: one for sufferers and the other for carers. The questionnaires were completed in their own time, and returned by Freepost. Each participant received a $£ 5$ gift voucher for their participation. For all scales, missing data were replaced by the individual mode for that scale, if no more than $50 \%$ of the items on the scale were missing. Otherwise, the scale value was considered as missing.

\section{Participants}

Forty-two individuals with OCD and their carers took part in this questionnaire study. Carer is defined as the person who the OCD sufferer mostly seeks reassurance from, or the person who is the closest to the sufferer (e.g. cohabitee) if they do not seek reassurance. The data of carers were matched with the data of their corresponding sufferers.

The mean age of carers was 44.49 years $(S D=13.09)$, of whom were 22 females and 20 were males. The relationship of carers to sufferers included girlfriend or boyfriend $(n=10)$, friend $(n=4)$, wife or husband $(n=16)$, mother or father $(n=8)$, child $(n=1)$, or others 
Table 1. Sufferer's general psychopathology

\begin{tabular}{|c|c|c|c|c|c|c|c|c|}
\hline & \multicolumn{2}{|c|}{ Total } & \multicolumn{2}{|c|}{$\begin{array}{c}\text { SCID } \\
\text { screened }\end{array}$} & \multicolumn{2}{|c|}{$\begin{array}{l}\text { Not SCID } \\
\text { screened }\end{array}$} & \multicolumn{2}{|c|}{$\begin{array}{l}\text { One-way } \\
\text { ANOVA }\end{array}$} \\
\hline & Mean & $S D$ & Mean & $S D$ & Mean & $S D$ & $F(1,41)$ & $p$ \\
\hline OCI total & 87.36 & 35.23 & 93.77 & 34.80 & 80.30 & 35.21 & 1.553 & .220 \\
\hline RAS & 134.00 & 31.19 & 133.23 & 36.80 & 134.85 & 24.50 & .028 & .869 \\
\hline RIQ & 56.16 & 28.11 & 54.54 & 28.82 & 71.57 & 18.12 & .652 & .429 \\
\hline BDI & 22.60 & 9.80 & 23.00 & 9.55 & 22.15 & 10.30 & .077 & .783 \\
\hline BAI & 25.76 & 13.71 & 26.64 & 13.36 & 24.80 & 14.36 & .184 & .670 \\
\hline ReSQ Source & 2.34 & 0.74 & 2.17 & 0.69 & 2.52 & 0.76 & 2.238 & .143 \\
\hline ReSQ Trust & 2.13 & 0.78 & 1.90 & 0.75 & 2.35 & 0.76 & 3.454 & .071 \\
\hline ReSQ Intensity & 1.93 & 0.77 & 1.70 & 0.73 & 2.20 & 0.75 & 4.698 & .036 \\
\hline ReSQ Carefulness & 3.32 & 0.74 & 3.13 & 0.74 & 3.54 & 0.68 & 3.572 & .066 \\
\hline
\end{tabular}

OCI, Obsessive-Compulsive Inventory; RAS, Responsibility Attitude Scale; RIQ, Responsibility Interpretations Questionnaire; BDI, Beck Depression Inventory; BAI, Beck Anxiety Inventory; ReSQ, Reassurance Seeking Questionnaire.

$(n=2)$. In terms of their occupational status, 29 of them were in education or employed, while 13 of them were unemployed.

The mean age of corresponding sufferers was 37.40 years $(S D=12.00)$. Although 22 sufferers (who were recruited from an out-patient service at the Institute of Psychiatry, King's College London) were diagnosed with OCD using the Structured Clinical Interview for DSMIV (SCID; First et al., 1996) by trained psychologists prior to participating in this study, 20 of them were self-diagnosed or diagnosed locally (e.g. by a General Practitioner or Primary Care Trust). However, one-way ANOVA confirmed that individuals with OCD who were SCID screened and those who were not did not significantly differ in terms of the total score for Obsessive-Compulsive Inventory - distress scale (Foa et al., 1998), Responsibility Attitude Scale (Salkovskis et al., 2000), Responsibility Interpretations Questionnaire (Salkovskis et al., 2000), Beck Depression Inventory (BDI; Beck and Steer, 1987), Beck Anxiety Inventory (Beck et al., 1988), and all the Reassurance-Seeking Questionnaire (Kobori and Salkovskis, 2013), except for the intensity scale (see Table 1).

\section{Questionnaire for carers}

Reassurance Seeking Questionnaire for Carers (ReSQ-C). This self-report scale was developed specifically for this study in order to look in detail at behaviours intended to provide reassurance when the OCD sufferers feel worried or anxious. ReSQ-C was first drafted by the first and second authors who have extensive experience in research and treatment of OCD, and then revised based on the comments and suggestions from two carers of the OCD sufferers. This questionnaire consists of three sections, and asks carers to report: (1) how they generally provide reassurance, (2) why they provide reassurance, and (3) how they think sufferers would feel when they provide or do not provide reassurance. Details of the scale are provided in the Results section. 


\section{Standardized measures for people with OCD}

Reassurance-Seeking Questionnaire (ReSQ; Kobori and Salkovskis, 2013). This questionnaire has four different scales and a separate section designed to assess emotional reactions:

(1) Source: this section enquires how frequently participants seek reassurance, consisting of 22 items.

(2) Trust: this section is about how much participants trust a range of sources of information, and consists of 16 items.

(3) Intensity: this section asks how many times participants seek the same reassurance until they stop, and consists of 16 items.

(4) Carefulness: this section measures how careful participants become when they are seeking reassurance, and consists of 11 items.

(5) Emotional changes: this section deals with how participants would feel when they receive or fail to receive reassurance. They rate different emotions in terms of how they would feel from 'much less' $(-5)$ to 'much more' $(+5)$ in three different situations: when the person they seek reassurance from does not answer, soon after they have received reassurance, and 20 minutes or more after they receive reassurance.

Structured Clinical Interview for Diagnostic and Statistical Manual of Mental Disorders (4th edition, DSM-IV) (SCID; First et al., 1996). This is a diagnostic instrument based on the DSM-IV criteria for psychiatric disorders. The SCID has been demonstrated to have acceptable reliability and validity (Segal et al., 1994).

Obsessive-Compulsive Inventory - distress scale (OCI-D; Foa et al., 1998). The OCI consists of 42 items composing seven subscales: washing, checking, doubting, ordering, obsessing (i.e. having obsessional thoughts), hoarding, and mental neutralizing. Each item is rated from 0 (has not troubled me at all) to 4 (troubled me extremely).

Responsibility Attitude Scale (RAS; Salkovskis et al., 2000). This 26-item self-report measure investigates general assumptions, attitudes and beliefs held about responsibility for harm to self and others. Every item consists of a statement about responsibility and asks individuals to rate how much they agree with it on a scale ranging from 'totally agree' to 'totally disagree'. Scores are calculated by summing all of the assigned values that range from a score of 1 for 'totally disagree' to a score of 7 for 'totally agree'. Salkovskis et al. (2000) reported that the RAS effectively discriminates between people with OCD and individuals with other anxiety disorders and non-clinical controls. The RAS has also been found to have high reliability and internal consistency (Salkovskis et al., 2000).

Responsibility Interpretations Questionnaire (RIQ; Salkovskis et al., 2000). This self-report measure was created to investigate the frequency of and degree of belief in individuals' interpretations (immediate appraisals) of specifically identified recent intrusions about harm coming to themselves or others. The RIQ has two subscales (belief and frequency), each with 22 responsibility appraisals. The items are the same on both subscales, but on the belief subscale the respondent is asked to rate how much they believe a responsibility appraisal on a scale of $0-100 \%$, whereas on the frequency subscale the respondent is asked to rate how frequently the responsibility appraisal occurred during the past week on a scale of 0 for never 
to 4 for always. Test-retest reliability and internal consistency are reported as good for adult populations (Salkovskis et al., 2000). In the current study, only the frequency part of the measure was used.

Beck Anxiety Inventory (BAI; Beck et al., 1988). This 21-item self-report measure assesses an individual's level of anxiety. Each question has four possible answers ranging from 0 'not at all', to 1 - 'mildly', 2 - 'moderately' and 3 - 'severely', and individuals are asked to rate each symptom of anxiety listed using this scale. The BAI has been reported to have high internal consistency and good test-retest reliability (Beck et al., 1988).

Beck Depression Inventory (BDI; Beck and Steer, 1987). This 21-item self-report measure is a well-validated measure of depression severity in adults and adolescents, although it is not diagnostic. The inventory assesses cognitive, behavioural and somatic features of depression over the past week.

\section{Results}

\section{General provision of reassurance}

This section firstly asks carers how often they are asked for reassurance, and how often they provide reassurance to OCD sufferers using a scale ranging from never (0), sometimes (1), often (2), to all the time (3).

Next, carers were asked to rate how frequently they provide reassurance in more detail, using a scale ranging from once a month or less (0), once a week (1), two or three times a week (2), every day (3), every hour (4), to all the time (5). They were also asked to rate how many times they provide the same reassurance until the sufferer stops to seek, using a scale ranging from never (0), once (1), two or three times (2), four or five times (3), to six times or more (4). Finally, they were asked to rate how much strain giving reassurance puts on them, using a scale ranging from not at all (0), slightly (1), moderately (2), very much (3), to extremely (4).

The results are presented in Table 2. Results show that reassurance was commonly asked for and provided directly, and indirect reassurance seeking and providing was less common. The majority of carers had provided reassurance with a particular set of words, and half of them had been asked to take part in sufferers' rituals. The majority of carers indicated that they provide reassurance every hour, they repeat the same reassurance two or three times, and giving reassurance moderately puts a strain on them.

\section{The relationship between carer's provision of reassurance and sufferer's psychopathology}

This section compares carer's ratings of their general behaviour of providing reassurance with sufferer's ratings of their OCD measures, depression, anxiety and reassurance seeking (see Table 3). Carer's rating of frequency of providing reassurance was correlated to sufferer's RIQ and BAI, and carer's rating of frequency of providing reassurance with a particular set of words was correlated to suffer's OCI total. However, ReSQ Source, ReSQ Trust and ReSQ Intensity were not correlated to any of carer's general behaviour of providing reassurance. Only sufferer's ReSQ carefulness, however, was correlated to carer's rating of being asked 
Table 2. Frequency of carer's general behaviour of providing reassurance

\begin{tabular}{|c|c|c|c|c|}
\hline Question items & Never & Sometimes & Often & All the time \\
\hline $\begin{array}{l}\text { Does he or she directly ask you for } \\
\text { reassurance? }\end{array}$ & $0(0 \%)$ & $14(33 \%)$ & $19(45 \%)$ & $9(22.2 \%)$ \\
\hline $\begin{array}{l}\text { Do you directly give reassurance to him } \\
\text { or her? }\end{array}$ & $0(0 \%)$ & $14(33 \%)$ & $23(55 \%)$ & $5(12 \%)$ \\
\hline $\begin{array}{l}\text { Does he or she indirectly ask you for } \\
\text { reassurance? }\end{array}$ & $2(5 \%)$ & $24(57 \%)$ & $11(26 \%)$ & $5(12 \%)$ \\
\hline $\begin{array}{l}\text { Do you indirectly give reassurance to } \\
\text { him or her? }\end{array}$ & $4(10 \%)$ & $25(60 \%)$ & $9(20 \%)$ & $4(10 \%)$ \\
\hline $\begin{array}{l}\text { Do they want you to respond with a } \\
\text { particular set of words? }\end{array}$ & $15(36 \%)$ & $15(36 \%)$ & $4(9 \%)$ & $8(19 \%)$ \\
\hline $\begin{array}{l}\text { Are you asked to take part in his or her } \\
\text { rituals? }\end{array}$ & $23(55 \%)$ & $11(27 \%)$ & $4(9 \%)$ & $4(9 \%)$ \\
\hline \multicolumn{5}{|l|}{ Question items } \\
\hline \multirow[t]{5}{*}{ How often do you give reassurance? } & \multicolumn{2}{|c|}{ Once a week } & \multicolumn{2}{|c|}{$3(7 \%)$} \\
\hline & \multicolumn{2}{|c|}{2 or 3 times a week } & \multicolumn{2}{|c|}{$7(17 \%)$} \\
\hline & \multicolumn{2}{|c|}{ Every day } & \multicolumn{2}{|c|}{$10(24 \%)$} \\
\hline & \multicolumn{2}{|c|}{ Every hour } & \multicolumn{2}{|c|}{$17(42 \%)$} \\
\hline & \multicolumn{2}{|c|}{ All the time } & \multicolumn{2}{|c|}{$2(5 \%)$} \\
\hline \multirow{5}{*}{$\begin{array}{l}\text { On average, how many times do you } \\
\text { give the same reassurance? }\end{array}$} & \multicolumn{2}{|l|}{ Never } & \multicolumn{2}{|c|}{$2(5 \%)$} \\
\hline & \multicolumn{2}{|l|}{ Once } & \multicolumn{2}{|c|}{$6(14 \%)$} \\
\hline & \multicolumn{2}{|c|}{2 or 3 times } & \multicolumn{2}{|c|}{$23(55 \%)$} \\
\hline & \multicolumn{2}{|c|}{4 or 5 times } & \multicolumn{2}{|c|}{$5(12 \%)$} \\
\hline & \multicolumn{2}{|c|}{6 times or more } & \multicolumn{2}{|c|}{$6(14 \%)$} \\
\hline \multirow{5}{*}{$\begin{array}{l}\text { Does giving reassurance put a strain on } \\
\text { you? }\end{array}$} & \multicolumn{2}{|c|}{ Not at all } & \multicolumn{2}{|c|}{$6(14 \%)$} \\
\hline & \multicolumn{2}{|c|}{ Slightly } & \multicolumn{2}{|c|}{$9(21 \%)$} \\
\hline & \multicolumn{2}{|c|}{ Moderately } & \multicolumn{2}{|c|}{$13(31 \%)$} \\
\hline & \multirow{2}{*}{\multicolumn{2}{|c|}{ Very much }} & \multicolumn{2}{|c|}{$12(29 \%)$} \\
\hline & & Extremely & \multicolumn{2}{|c|}{$2(5 \%)$} \\
\hline
\end{tabular}

for reassurance, being indirectly asked for reassurance, indirect provision of reassurance, and provision of reassurance with a particular set of words.

\section{Motivation to provide reassurance}

Carers were asked to specify their understanding of the reasons they provide reassurance. They rated 12 items from totally disagree (0) to totally agree (6). The items were developed by OCD experts with the consultation of two carers of chronic sufferers of OCD. In the results in Table 4, items were sorted according to the mean score. This result suggests that carers do not generally believe that reassurance solves the problem or that bad things will happen without providing reassurance, but they cannot help providing it. They also feel that providing reassurance shows that they are supporting sufferers (see Table 4). 
Table 3. Correlation between the carer's ratings and the corresponding sufferer's ratings

\begin{tabular}{|c|c|c|c|c|c|c|c|c|c|}
\hline $\begin{array}{l}\text { Sufferer's ratings } \\
\text { Carer's ratings }\end{array}$ & $\begin{array}{l}\text { OCI } \\
\text { total }\end{array}$ & RAS & RIQ & BDI & BAI & $\begin{array}{l}\text { ReSQ } \\
\text { Source }\end{array}$ & $\begin{array}{l}\text { ReSQ } \\
\text { Trust }\end{array}$ & $\begin{array}{l}\text { ReSQ } \\
\text { Intensity }\end{array}$ & $\begin{array}{l}\text { ReSQ } \\
\text { Carefulness }\end{array}$ \\
\hline $\begin{array}{l}\text { Does he or she directly ask you for } \\
\text { reassurance? }\end{array}$ & .229 & -.069 & .223 & .119 & .227 & .182 & .123 & .222 & $.334^{* * *}$ \\
\hline Do you give reassurance to him or her? & .203 & -.055 & $.434^{*}$ & .070 & $.253^{*}$ & .043 & .113 & 200 & .214 \\
\hline $\begin{array}{l}\text { Does he or she indirectly ask you for } \\
\text { reassurance? }\end{array}$ & .123 & -.045 & .043 & .069 & .114 & .104 & .225 & . 157 & $.375^{* *}$ \\
\hline $\begin{array}{l}\text { Do you indirectly give reassurance to } \\
\text { him or her? }\end{array}$ & .133 & .131 & .000 & .149 & .163 & .150 & .193 & .099 & $.242^{*}$ \\
\hline $\begin{array}{l}\text { Do they want you to respond with a } \\
\text { particular set of words (for example, } \\
\text { 'you are clean')? }\end{array}$ & $.237^{*}$ & -.023 & .256 & .227 & .176 & .168 & .176 & .086 & $.286^{*}$ \\
\hline $\begin{array}{l}\text { Are you asked to take part in his or her } \\
\text { rituals? }\end{array}$ & .100 & -.212 & -.246 & .126 & .028 & .002 & -.027 & -.184 & -.054 \\
\hline How often do you give reassurance? & .115 & -.011 & .205 & .081 & .138 & -.110 & -.238 & -.045 & -.029 \\
\hline $\begin{array}{l}\text { On average, how many times do you give } \\
\text { the same reassurance until the person } \\
\text { lets you stop? }\end{array}$ & -.042 & -.019 & -.192 & .134 & .041 & .148 & .184 & .002 & .027 \\
\hline $\begin{array}{l}\text { Does giving reassurance put a strain on } \\
\text { you? }\end{array}$ & -.135 & $-.284^{*}$ & -.133 & -.041 & -.233 & -.003 & .068 & -.035 & -.163 \\
\hline
\end{tabular}

OCI, Obsessive-Compulsive Inventory; RAS, Responsibility Attitude Scale; RIQ, Responsibility Interpretations Questionnaire; BDI, Beck Depression Inventory; BAI, Beck Anxiety Inventory; ReSQ, Reassurance Seeking Questionnaire. ${ }^{*} p<.05,{ }^{* *} p<.01,{ }^{* * *} p<.001$. 
Table 4. Carer's rating of the motivations to provide reassurance

\begin{tabular}{llc}
\hline Items & Mean & $S D$ \\
\hline It shows that I'm providing support & 4.71 & 1.35 \\
It shows how much I care for the person & 4.57 & 1.67 \\
If I don't give reassurance, their anxiety will become unbearable to them & 4.48 & 1.49 \\
I don't know what else to do & 4.21 & 1.54 \\
I do not have alternatives & 4.00 & 1.77 \\
It is my habit: I give reassurance without thinking & 3.45 & 1.94 \\
The person will not leave me alone unless I give reassurance & 3.29 & 2.22 \\
I get too tired to do anything else & 3.02 & 2.01 \\
I'm afraid that something awful will happen if I don't give reassurance & 2.90 & 2.24 \\
If I don't give reassurance, he or she will become angry & 2.88 & 2.04 \\
I can make his or her obsessional problems better by giving reassurance & 2.81 & 1.90 \\
\hline
\end{tabular}

Items were rated from 0 (totally disagree) to 6 (totally agree).

Table 5. Carer and sufferer's rating of feeling reassured and anxious across situations

\begin{tabular}{|c|c|c|c|c|c|}
\hline \multirow[b]{2}{*}{ Emotions } & \multirow[b]{2}{*}{ Situations } & \multicolumn{2}{|c|}{$\begin{array}{l}\text { Carer's } \\
\text { prediction }\end{array}$} & \multicolumn{2}{|c|}{$\begin{array}{l}\text { Sufferer's } \\
\text { rating }\end{array}$} \\
\hline & & Mean & $S D$ & Mean & $S D$ \\
\hline \multirow[t]{3}{*}{ Feeling reassured } & No reassurance & -2.58 & 2.04 & -3.66 & 1.74 \\
\hline & Short term & 1.65 & 1.85 & 3.02 & 1.54 \\
\hline & Middle term & 0.98 & 2.18 & 1.39 & 2.45 \\
\hline \multirow[t]{3}{*}{ Feeling anxious } & No reassurance & 2.98 & 2.13 & 3.61 & 2.01 \\
\hline & Short term & -1.20 & 2.02 & -1.46 & 2.53 \\
\hline & Middle term & 0.10 & 2.32 & 0.61 & 2.68 \\
\hline
\end{tabular}

Carers were asked to rate how reassured and anxious they think sufferers would feel in three different situations: when they do not provide reassurance (no reassurance), soon after they provide reassurance (short term), and 20 minutes or more after they provide reassurance (middle term). They rated how emotions would change from much less ( -5$)$ to much more $(+5)$. These data were compared with the ratings of the sufferers. Thus sufferers were asked to rate how anxious and reassured they would feel in the three situations described above (see Table 5).

A $3 \times 4$ mixed model ANOVA was conducted to compare the groups (carer and sufferer) in terms of the rating of feelings reassured across the situations (no reassurance, short term, and middle term). The ANOVA revealed no significant main effect of group: $F(1,83)=0.651$, $p=.422$. However, there was a significant main effect of situation: $F(2,82)=200.455, p<$ .001 ; and there was a group $\times$ situation interaction: $F(2,82)=9.310, p<.001$ (see Fig. 1 ).

Because the interaction was significant, post-hoc analyses of simple main effects using Bonferroni's method were conducted to compare each score within each group and within each situation. This analysis revealed that in the carer group, the score for feeling reassured when no reassurance was provided was smaller than at short term $(p<.001)$ and middle term $(p<.001)$, but the score at short term and middle term were not significantly different 


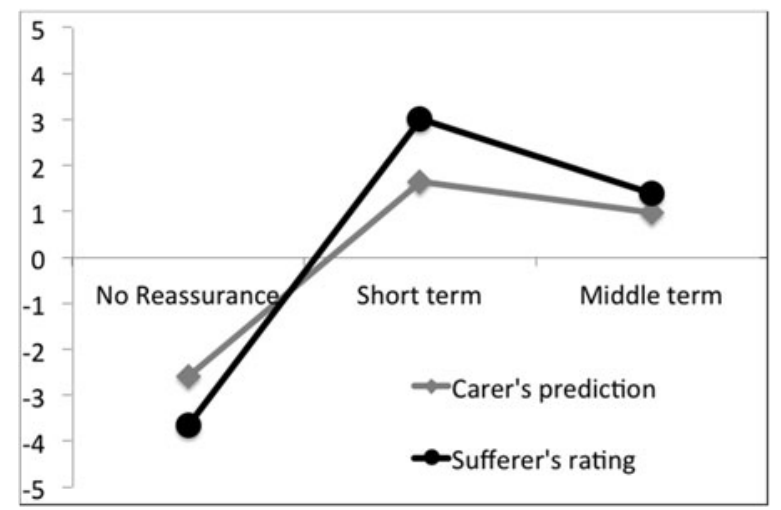

Fig. 1. Carer and sufferer's rating of feeling reassured across situations

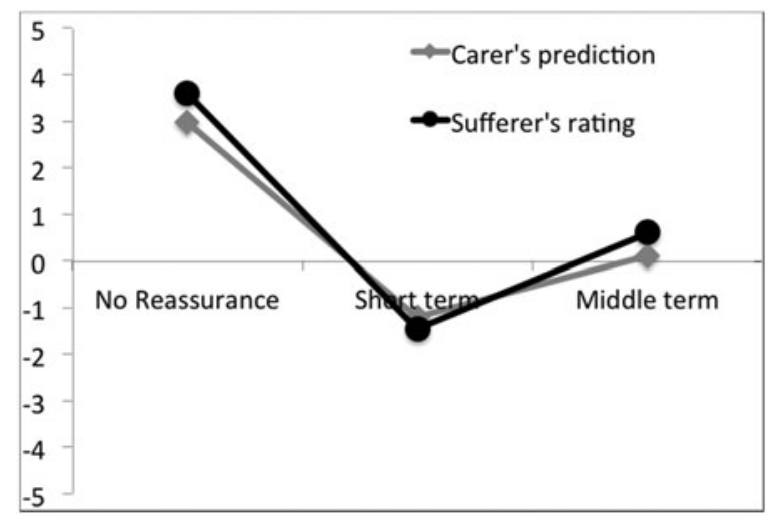

Fig. 2. Carer and sufferer's rating of feeling anxious across situations

$(p=.177)$. In the sufferer group, the score for feeling reassured at short term was greater than at middle term $(p<.001)$, and the score at short term was greater than no reassurance $(p<.001)$. Carer's rating for feeling reassured was greater than sufferer at no reassurance $(p=.012)$, and smaller at short term $(p<.001)$. There was no difference between carer and sufferer at middle term $(p=.423)$.

A $3 \times 4$ mixed model ANOVA was conducted to compare the groups (carer and sufferer) in terms of the rating of feelings anxious across the situations (no reassurance, short term, and middle term). The ANOVA revealed no significant main effect of group: $F(1,83)=0.625, p=$ .432 , and for interaction: $F(2,82)=1.288, p=.279$. However, there was a significant main effect for situation: $F(2,82)=119.160$. Post-hoc multiple comparisons using Bonferroni's method revealed that the rating of feeling anxious was greater at no reassurance than middle term $(p<.001)$, and greater at middle term than short term (see Fig. 2).

\section{Discussion}

The purpose of the present study was to explore carers' experience of reassurance provision and its relationship to the psychopathology of OCD sufferers. Specifically, we examined 
how caregivers and OCD sufferers feel when reassurance is provided versus not provided, as well as investigating caregiver's motivations for giving reassurance. In addition, this study examined how accurately carers perceive the effect of reassurance provision and not giving reassurance by comparing the data obtained from the sufferers of OCD.

\section{Carer's perception of reassurance seeking and providing}

From the carers' viewpoint, reassurance is commonly sought and provided directly (e.g. verbally responding to the obvious request of reassurance), and they are less aware of subtle reassurance seeking. This result is consistent with our qualitative study (Kobori et al., 2012), and suggests that individuals with OCD carefully compose questions so they can elicit a more convincing answer and/or seek reassurance in hidden (or subtle) ways and so that the other person does not notice that reassurance is being sought. This appears at least in part to occur because both the carer and the suffer know, through therapy and their own experiences that reassurance is ultimately counter-productive (Halldorsson et al., 2016; Kobori et al., 2012). In addition to being asked for the same reassurance repeatedly, the majority of carers provide reassurance with a specific set of words and phrases, to perhaps maximize the calming effect of reassurance. Sufferers may become frustrated when the carer even slightly changes the words to reassure them, and they may ask for the reassurance again and again when it is not provided in the way they want. Regarding the motivation for carers to provide reassurance, the result suggests that carers do not generally believe that reassurance solves the problem or that objectively bad things will happen without providing reassurance, but they feel emotionally bound to provide it. They also feel that providing reassurance shows that they are supporting sufferers. Carers may feel helpless because they think that the only thing they can do to support the sufferer would be to offer reassurance, even though they know it does not solve the problem.

Correlations between the carers' scores and the sufferers' scores generally demonstrate that carer's behaviours in providing reassurance are associated with how carefully sufferers seek reassurance. Specifically, the more carefully sufferers seek reassurance, the more frequently carers report they are asked for reassurance. When sufferers become very careful, they make sure that the person giving feedback is seriously thinking about their answer, pay close attention to how the person answered, analyse whether the answer makes sense or whether there are any mistakes or inconsistencies in the answer, and they show frustration if the answer is not quite what they hoped for. This result is somewhat different to the findings of Boeding et al. (2013) that the partner's accommodation is associated with greater OCD symptom severity, but in line with our previous finding that the frequency and intensity (i.e. how many times they repeat the same reassurance seeking until they stop) of verbal reassurance seeking from other people is not significantly different between individuals with OCD, panic and healthy controls (Kobori and Salkovskis, 2013). Sufferer's carefulness was also correlated with carer's perception of indirect reassurance seeking and indirect reassurance provision. This may support the view that sufferers become particularly careful when they indirectly seek and receive reassurance, such as such as composing a trick question so that other people do not notice reassurance seeking (Kobori et al., 2012).

The results comparing how carers think sufferers would feel and how sufferers report that they would actually feel suggest that carer's perspectives on the impact of reassurance provision proved to be almost entirely accurate; both sufferers and carers perceive that 
reassurance works only temporarily, but even if the anxiety-relieving effect of reassurance decreases in the middle term, it is likely to be perceived as beneficial because they accurately perceived that sufferers would feel much worse if carers refuse to provide reassurance. The slight differences found in this study were that sufferers would feel even less reassured than carers imagine when they do not provide reassurance, and sufferers would feel even more reassured in the short term, suggesting that the need of sufferers is even stronger than carers believed.

The results support the notion that although it has been normally assumed that when people seek reassurance they obtain reassurance, reassurance seeking can be analysed into multiple components. These components may involve perceiving threat (and responsibility), urge to seek reassurance, composing the way to seek reassurance, (verbally) asking for reassurance, processing the response, examining the impact of the process and the response on the original threat and/or emotions, and processing the other person's response to the reassurance seeking. These components can be classified into two higher-level categories: (1) attempting to deal with threat and responsibility, and (2) processing feedback derived from the outcome of intended action. This distinction is relevant, given that individuals with OCD seek reassurance regardless of whether they obtain it or not; this is consistent with the clinical observation that individuals with OCD sometimes do not seem to care how clean they become, but they wash their hands anyway.

\section{Clinical implications}

The findings of the present study yield several clinical implications in relation to reassurance seeking and its provision. Firstly, clinicians need to be aware of the carefulness of reassurance seeking, which was related to carer's perception of being asked for reassurance. When clinicians manage reassurance seeking in therapy, they should pay attention not only to the frequency and duration of reassurance seeking, but also to how carefully it is sought. Reducing carefulness may reduce carers' distress regarding reassurance providing, as well as challenge sufferers' beliefs about threat and responsibility.

The present study demonstrated that sufferers feel reassured in the short term, and while the anxiety comes back in the mid-term, it is still (much) better than no reassurance. Moreover, carer's perception of this impact of reassurance was accurate. Before involving a family member or carer as a co-therapist, acknowledging carers' struggles, and motivations to provide reassurance would help them feel understood by the therapist, thereby enhancing their collaboration in the therapy. Abramowitz et al. (2013) introduced the alternatives to the accommodation, such as teaching partners how to be supportive by providing esteem support and encourage the sufferer to 'get through' the anxiety until it habituates, rather than trying to avoid or neutralize it for the sufferer. This may also reduce criticism and hostility within the family, which are found to be associated with greater symptom severity and worse treatment outcome (Chambless and Steketee, 1999; Renshaw et al., 2003; Van Noppen and Steketee, 2009). Furthermore, cognitive behavioural therapy that focuses on treating excessive reassurance seeking by helping OCD sufferers to shift from seeking reassurance to seeking support is a particularly promising development (Halldorsson et al., 2016). As an example, an OCD sufferer may tell a trusted person how bad he/she feels and how difficult he/she finds it not to give in to the compulsion to check and within that context asks for encouragement and 
support to overcome the urge to check, as opposed to asking for reassurance that the feared catastrophe is not going to happen.

Finally, direct or subtle reassurance seeking also tends to occur in the course of therapy, most commonly without the sufferer being aware that 'just mentioning' something they did as part of therapy to the therapist is problematic. In addition, therapist-directed exposure and behavioural experiments could, under some circumstances, act to provide inappropriate reassurance and hence unwittingly lead to failure of response prevention (Salkovskis, 1999). Thus it is important to identify how clinicians judge whether the request from sufferers can be characterized as reassurance seeking, how they identify subtle and indirect reassurance seeking from sufferers, and how they respond when they are asked for reassurance.

\section{Limitations and future directions}

Because the sample size is relatively small in the present study, further validation studies with larger samples are required to ensure the generalizability of the findings. Another issue is that the clinical samples were limited to individuals with OCD. It remains unknown whether carers of other anxiety disorders (e.g. panic, health anxiety, social phobia, specific phobia, etc.) have similar or different experiences in providing reassurance. It should also be acknowledged that a subgroup of individuals with OCD had no verified diagnoses. Although individuals who were SCID screened and those who were not did not significantly differ in most of measures for psychopathology, this limits the generalizability of our findings. Additionally, this study did not exclude psychopathological disorders in the carers' group.

Further, this study did not measure the frequency of the interaction between the carer and sufferer, and did not include the type of interaction. For example, a parent of the OCD sufferer would have different experiences compared with a friend of the OCD sufferer. There is also a possibility that the sufferer and the carer might have influenced each other when they filled in the questionnaires. For example, the suffer may want to check how the carer responds to the questions or they try to agree how often they seek and provide reassurance. Finally, the sample of the present study was limited to the English-speaking population. The questionnaire should be implemented with individuals who speak other languages and individuals with different cultural backgrounds. The present study suggests that carers do not generally believe that reassurance solves the problem or that bad things will happen without it. This result may be influenced by psycho-education, which was given when sufferers receive cognitive behavioural therapy (CBT). Thus in other countries where interpersonal relationships are different from those in the UK or CBT is not widely available, carers may provide reassurance for other reasons, and may believe that reassurance solves the problem.

\section{Main points}

(1) 42 people with OCD and their carers were asked about reassurance seeking and providing.

(2) Frequency of reassurance provision is associated with how carefully sufferers seek.

(3) Both sufferers and carers know that reassurance works only temporarily.

(4) Carers perceive that sufferers would feel much worse if they do not provide reassurance.

(5) It would not be helpful to simply ask carers to stop providing reassurance. 


\section{Acknowledgements}

None.

\section{Financial support}

This work was supported by a Postdoctoral Fellowship for Research Abroad from the Japan Society for Promotion of Science (Social Science 728).

\section{Ethical statement}

We have abided by the Ethical Principles of Psychologists and Code of Conduct as set out by the APA. This project has been reviewed by the Joint South London and Maudsley and the Institute of Psychiatry NHS Research Ethics Committee (REC reference: 07/Q0706/39).

\section{Conflicts of interest}

We have no conflicts of interest with respect to this publication

\section{Suggested further reading}

Challacombe F, Oldfield VB, Salkovskis PM (2011). Break Free From OCD: Overcoming Obsessive Compulsive Disorder with CBT. Random House.

Halldorsson B, Salkovkis PM, Kobori O, Pagdin R (2016). I do not know what else to do: Caregivers' perspective on reassurance seeking in OCD. Journal of Obsessive-Compulsive and Related Disorders 8, 21-30.

Kobori O, Salkovskis PM, Read J, Lounes N, Wong V. (2012). A qualitative study of the investigation of reassurance seeking in obsessive-compulsive disorder. Journal of Obsessive-Compulsive and Related Disorders 1, 25-32.

\section{References}

Abramowitz JS, Baucom DH, Wheaton MG, Boeding S, Fabricant LE, Paprocki C, Fischer MS (2013). Enhancing exposure and response prevention for OCD: a couple-based approach. Behavior Modification 37, 189-210.

Abreu Ramos-Cerqueira ATD, Torres AR, Torresan RC, Negreiros APM, Vitorino CN (2008). Emotional burden in caregivers of patients with obsessive-compulsive disorder. Depression and Anxiety 25, 1020-1027.

Amir N, Freshman M, Foa EB (2000). Family distress and involvement in relatives of obsessivecompulsive disorder patients. Journal of Anxiety Disorders 14, 209-217.

Beck AT, Epstein N, Brown G, Steer RA (1988). An inventory for measuring clinical anxiety: psychometric properties. Journal of Consulting and Clinical Psychology 56, 893-897.

Beck AT, Steer RA (1987). Manual for the Beck Depression Inventory. San Antonio: Psychological Corporation.

Black DW, Gaffney G, Schlosser S, Gabel J. (1998). The impact of obsessive-compulsive disorder on the family: preliminary findings. Journal of Nervous and Mental Disease 186, 440-442. 
Boeding SE, Paprocki CM, Baucom DH, Abramowitz JS, Wheaton MG, Fabricant LE, Fischer MS (2013). Let me check that for you: symptom accommodation in romantic partners of adults with obsessive-compulsive disorder. Behaviour Research and Therapy 51, 316-322.

Cicek E, Cicek IE, Kayhan F, Uguz F, Kaya N (2013). Quality of life, family burden and associated factors in relatives with obsessive-compulsive disorder. General Hospital Psychiatry 35, 253-258.

Calvocoressi L, Lewis B, Harris M, Trufan SJ, Goodman WK, McDougle CJ, Price LH (1995). Family accommodation in obsessive-compulsive disorder. American Journal of Psychiatry 152, 441443.

Calvocoressi L, Mazure C, Kasl S, Skolnick J, Fisk D, Vegso SJ, Van Noppen BL, Price LH (1999). Family accommodation of obsessive-compulsive symptoms: instrument development and assessment of family behavior. Journal of Nervous and Mental Disease 187, 636-642.

Chambless DL, Steketee G (1999). Expressed emotion and behavior therapy outcome: a prospective study with obsessive-compulsive and agoraphobic outpatients. Journal of Consulting and Clinical Psychology 67, 658-665.

Cooper M (1996). Obsessive-compulsive disorder: effects on family members. American Journal of Orthopsychiatry 66, 296-304.

Derisley J, Libby S, Clark S, Reynolds S (2005). Mental health, coping and family-functioning in parents of young people with obsessive-compulsive disorder and with anxiety disorders. British Journal of Clinical Psychology 44, 439-444.

First M, Spitzer R, Gibbon M, Williams J (1996). Structured clinical interview for DSM-IV axis I disorders - patient edition. New York.

Foa EB, Kozak MJ, Salkovskis PM, Coles M, Amir N (1998). The validation of a new obsessivecompulsive disorder scale: the obsessive-compulsive inventory. Psychological Assessment 3, 206214.

Grunes MS, Neziroglu F, McKay D (2001). Family involvement in the behavioral treatment of obsessive-compulsive disorder: a preliminary investigation. Behavior Therapy 32, 803-820.

Grover S, Dutt A (2011). Perceived burden and quality of life of caregivers in obsessive-compulsive disorder. Psychiatry and Clinical Neurosciences 65, 416-422.

Halldorsson B, Salkovkis PM, Kobori O, Pagdin R. (2016). I do not know what else to do: caregivers' perspective on reassurance seeking in OCD. Journal of Obsessive-Compulsive and Related Disorders 8, 21-30.

Kalra H, Nischal A, Trivedi JK, Dalal PK, Sinha PK (2009). Extent and determinants of burden of care in Indian families: a comparison between obsessive-compulsive disorder and schizophrenia. International Journal of Social Psychiatry 55, 28-38.

Kobori O, Salkovskis PM (2013). Patterns of reassurance seeking and reassurance-related behaviours in OCD and anxiety disorders: the development of the reassurance seeking questionnaire. Behavioural and Cognitive Psychotherapy 41, 1-23.

Kobori O, Salkovskis PM, Read J, Lounes N, Wong V (2012). A qualitative study of the investigation of reassurance seeking in obsessive-compulsive disorder. Journal of Obsessive-Compulsive and Related Disorders 1, 25-32.

Lebowitz ER, Panza KE, Bloch MH. (2016). Family accommodation in obsessive-compulsive and anxiety disorders: a five-year update. Expert Review of Neurotherapeutics 16, 45-53.

Lochner C, Mogotsi M, du Toit PL, Kaminer D, Niehaus DJ, Stein DJ (2003). Quality of life in anxiety disorders: a comparison of obsessive-compulsive disorder, social anxiety disorder, and panic disorder. Psychopathology 36, 255-262.

Rachman S (2002). A cognitive theory of compulsive checking. Behaviour Research and Therapy $\mathbf{4 0}$, 625-639.

Renshaw KD, Chambless DL, Steketee G (2003). Perceived criticism predicts severity of anxiety symptoms after behavioral treatment in patients with obsessive-compulsive disorder and panic disorder with agoraphobia. Journal of Clinical Psychology 59, 411-421. 
Salkovskis PM (1999). Understanding and treating obsessive-compulsive disorder. Behaviour Research and Therapy 37, S29-52.

Salkovskis PM, Wroe AL, Gledhill A, Morrison N, Forrester E, Richards C, Reynolds M, Thorpe S (2000). Responsibility, attitudes and interpretations are characteristic of obsessive compulsive disorder. Behaviour Research and Therapy 38, 347-372.

Segal DL, Hersen M, Van Hasselt VB (1994). Reliability of the Structured Clinical Interview for DSM-III-R: an evaluative review. Comprehensive Psychiatry 35, 316-327.

Shafran R, Ralph J, Tallis F (1995). Obsessive-compulsive symptoms and the family. Bulletin of the Menninger Clinic 59, 472-479.

Steketee G (1997). Disability and family burden in obsessive-compulsive disorder. Canadian Journal of Psychiatry 42, 919-928.

Steketee G, Pruyn NA (1998). Families of individuals with obsessive-compulsive disorder. ObsessiveCompulsive Disorder: Theory, Research, and Treatment, pp. 120-140. Guilford Press.

Stein DJ, Roberts M, Hollander E, Rowland C, Serebro P (1996). Quality of life and pharmacoeconomic aspects of obsessive-compulsive disorder. A South African survey. South African medical Journal [ = Suid-Afrikaanse tydskrif vir geneeskunde] 86, 1579-1582.

Storch EA, Lehmkuhl H, Pence SL, Geffken GR, Ricketts E, Storch JF, Murphy TK (2009). Parental experiences of having a child with obsessive-compulsive disorder: associations with clinical characteristics and caregiver adjustment. Journal of Child and Family Studies 18, 249-258.

Torres AR, Hoff NT, Padovani CR, Ramos-Cerqueira AT (2012). Dimensional analysis of burden in family caregivers of patients with obsessive-compulsive disorder. Psychiatry and Clinical Neurosciences 66, 432-441.

Van Noppen B, Steketee G (2009). Testing a conceptual model of patient and family predictors of obsessive compulsive disorder (OCD) symptoms. Behaviour Research and Therapy 47, 18-25.

Veltro F, Magliano L, Lobrace S, Morosini PL, Maj M. (1994). Burden on key relatives of patients with schizophrenia vs neurotic disorders: a pilot study. Social Psychiatry and Psychiatric Epidemiology 29, 66-70.

Vikas A, Avasthi A, Sharan P (2011). Psychosocial impact of obsessive-compulsive disorder on patients and their caregivers: a comparative study with depressive disorder. International Journal of Social Psychiatry 57, 45-56.

\section{Learning objectives}

(1) To develop an awareness of how carers of OCD sufferers struggle with reassurance providing.

(2) To gain an increased understanding of why it is difficult for OCD sufferers to stop seeking reassurance.

(3) To gain an increased understanding of why carers of OCD sufferers are unable to refuse to provide reassurance. 